\title{
Business Intelligence and Advanced Analytics: Impact and Behavior of Business Decision Making Process
}

\author{
S. Ganesan, S. Gopalsamy
}

\begin{abstract}
In the current situation, numerous ways are available for the support of leaders, but decision making in an organization are still susceptible to flaws and errors. Among several approaches, Business Intelligence and Advanced Analytics (BI\&AA) is considered a valid tool to managers in the pragmatic decision on the basis of well-informed evidence. In spite of high investment, there is a massive backdrop in this BI\&AA project. Managers have aided with numerous guidelines in making decisions, and those guidelines include information from research works, then things based on guts, and on data that are available. With the help of various experiments, this research has done to investigate whether the information available for decision making affects the mind of the managers or its influence cause change in decision outcome. This research outcome with both descriptive and prescriptive decision theories and further existing literature in the field of BI. As per the result of this research study, remedies are given to improve BI\&AA solutions.
\end{abstract}

Keywords : Business Intelligence, Data Analytics, Bigdata, Decision Making.

\section{INTRODUCTION}

In this cut-throat society Business intelligence and Advanced analytics (BI\&AA) is one of the fastest-growing industries - market forecasts to reach $\$ 18.3$ billion in 2017 , an increase of 7.3 percent from 2016; further by the end of 2020, market aims to leap to $\$ 22.8$ billion[1]. Over the last decade, the role of BI\&AA has increased drastically. According to Gartner's CIO survey, BI\&AA will be the most important technology area to help businesses to varied from their competitors in 2018[2]. According to the study of 154 global executives, conducted by the Economist Intelligence Unit, useful data is the most prominent input for making a decision[3]. Although there are huge investments done, a survey conducted by Paradigm4 in 2014 highlights that $49 \%$ of respondents of stumbling to manage and process their existing relational databases[4], Gartner foresees that, at the time of 2017, 60 percent of big data projects fail to

Revised Manuscript Received on October 15, 2019.

* Correspondence Author

S.GANESAN, Ph.D Research Scholar, Department of International Business, Alagappa University Karaikudi, Tamil Nadu, India

Dr. S. GOPALSAMY, Assistant Professor, Department of International Business, Alagappa University Karaikudi, Tamil Nadu, India. withstand piloting and experimentation, and will be abandoned[5].

Table 1: Comparison Business Intelligence vs Advanced analytics

\begin{tabular}{|c|c|c|}
\hline & Business T intelligence & $\begin{array}{l}\text { AdvancedT } \\
\text { Analytics }\end{array}$ \\
\hline $\begin{array}{l}\text { Answer the } \\
\text { questions : }\end{array}$ & $\begin{array}{l}\text { - What Happened? } \\
\text { - When? } \\
\text { - Who? } \\
\text { - How Many? }\end{array}$ & $\begin{array}{l}\text { - Why did it } \\
\text { Happen? } \\
\text { - Will it Happen } \\
\text { Again? } \\
\text { - What will } \\
\text { happen if we } \\
\text { change x? } \\
\text { - What else does } \\
\text { the data tell us } \\
\text { that we never } \\
\text { thought to } \\
\text { ask? }\end{array}$ \\
\hline
\end{tabular}

- Reporting (KPIs Metrics)

- Automated Monitoring and Alerting(thresholds )

Includes :

- Dashboards

- Scoreboards

- OLAP (cubes, slice and dice, drilling)

- Ad hoc query

- Operational and real-time BI

- Statistical or quantitative analysis

- Data Mining

- Predictive modelling

- Multivariate Testing

- Big Data Analytics

- Text Analytics

Numerous peer researches have done on analyzing the reason for BI\&AA project failures, and its result shows a common pattern of ideas. Forrester Consulting's study of Traditional BI performed in 2014 indicates that $60 \%$ of professionals have time concerns with creating and updating dashboards[6]. According to Oracle's survey in

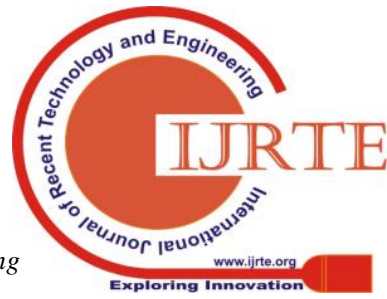


2012, "Big Data, Bigger Opportunities: Plans and Preparedness for the Data Deluge," $45 \%$ of respondents struggle to report information to business managers as possible as they need it[7]. As per Columbia Business School's research, $39 \%$ of marketers convey that their data is gathered "too infrequently or not real-time enough"[8]. Business intelligence is sometimes used interchangeably with business analytics. In other cases, business analytics is used either more narrowly to refer to advanced data analytics or more broadly to include both BI and advanced analytics. Table I described a Comparison of BI and advanced analytics.

Through all these research results, we can conclude that adequate information delivery in the time when it is needed is essential as well as tough tasks in BI\&AA, which very often fails. Though investment in real-time BI\&AA will help to avoid these problems, still there is an unanswerable question, whether would it have any impact on the behavior of business decision-makers.

\section{REVIEW OF LITERATURE}

\section{A. Decision Theories}

Decision theory has its long history in this branch of decision making. For about a decade, it has studied under various angles, yet managers face difficulties in applying their findings in practice. There are three different approaches with different assumptions and criteria, and those are normative, descriptive, and prescriptive theories. In normative decision theory, people focus on how people took the decision and evaluated it through theories. In descriptive decision theory, the evaluation has based on empirical validity; and focuses on how and why people think and proceed with their decision. But the later prescriptive decision theory gets the contrast to the above discussed two. Prescriptive models focus on the way of the betterment of decision making, and all has done in a clear, optimistic, and pragmatic way.

A normative approach implicates a few rules and standards for decision under risks. From the view of Shapira, two rules ought to be applicable and has expected value rule and expected utility rule[4]. The former is a weighted average of possible outcomes that are all weighted by their probabilities. These propose to choose an alternative with the most expected value. It would expect the highest chance of winning up to $90 \%$ i.e, $\$ 1000$ and least of $10 \%$ i.e, $\$ 10$, therefore the expected estimation will be $0.90 * 1000+0.10 * 10=901$ its far better than having $\$ 900$ with conformity. Bernoulli extended this rule on the vein of the value of the item must not be based on the price but its utility (psychological value). He suggests that people's decision has paralleled to the range of their wealth, and so expected value is the average of utilities of these outcomes weighted by probability. From the view of Bernoulli's wealthier people will prefer riskier alternatives as they are emotionally less affected by gain.

Further, he put forth the principle that is known as the diminishing marginal utility of wealth by indicating that any next increment of wealth is inversely proportionate to the amount of wealth already gained [2]. Jensen views Bernoulli's approach expressing concerns about unbounded logarithmic function serves as a utility function. He claims that it ought to be finite. In continuation of that, he questions why there are no other variables used together with the expected value to determine preferences [3].

Further axiomatization of linear expected utility originated by von Neumann and Morgenstern sets a new fundamental theory of expected utility theory. He proves this by saying for rational individuals who prefer certain axioms (completeness, transitivity, independence, continuity) will fulfill the expected utility function, thus leads to gain maximum utility [4]. It is not only expected as a normative model but also as a descriptive model of the decision maker's behavior.

Both rationality theory and prospect theory will provide an application of expected utility theory as a descriptive model at the fundamental level. Simon says as per bounded rationality theory, rational choices consider cognitive limitations of the decision-maker - with the limitations of both knowledge and computational capacity. He also advises that bounded by cognitive limitations, decision-makers look for fulfillment rather than optimal alternative [5]. As per Simon, decision making undergoes three principal phases:

1. Intelligence - searching the apt environment for conditions calling for decision;

2. Design - inventing, developing and analyzing possible courses of action;

3. Choice - selecting a particular course of action from those available [6].

Prospect theory shares its idea with Bernoulli's expected utility theory to analyze the psychological value of decision outcomes, which differs from expected utility theory in many fundamental ways. In prospect theory [7], which is originated by Kahneman and Tversky, choices preferred by people are assessed by S-shaped value function, which is concave for gains and convex and steeper for losses. The value of every result has multiplied by a decision weight that has inferred from choices between prospects. Primarily weight age of decision depends on the perceived likelihood of preference or event, but they are not probabilities. Indifference to Bernoulli's theory, the 
usage of gain is valued depending on the state of wealth; prospect theory includes three principles that influence the value of outcomes: neutral reference point, diminishing sensitivity principle, and reflection effect [8].

Decision outcomes has considered as gains and losses as per the neutral reference point, which can be as well the status quo as the expected outcome. If the outcome is much better, the reference point has considered as gain and which are worse than the reference point is losses.

As per the diminishing sensitivity principle, the estimated value of both gains and losses generally fall with their magnitude. It means that the difference between 100 and 200 is more valuable than the same difference between 1100 and 1200.

The third principle indicates - reflection effect - people are risk-seeking in choices between negative and positive prospects, the former leads to a loss, that is smaller loss in certain; while the latter leads to a larger gain. It means in case of having an $80 \%$ chance of winning $\$ 4,000$ or having $\$ 3,000$ with certainly, the majority of people choose the latter option while in case of losing $\$ 4,000$ with $80 \%$ probability of losing $\$ 3,000$ with certainty, so the masses would prefer the firsts choice.

The main focus of Prescriptive decision theory is on the application of normative and descriptive models to aid in solving real-life problems, by analyzing a single problem at a time and looking for the best possible solution. Over the last decade, the role of prescriptive decision analysis in solving myriad complex is noteworthy. The purpose is to provide the best decision for a particular situation. Based on both common sense and logical axioms, decision analysis simplifies decisions by breaking them into parts but does not oversimplify it to be able to address the complexity of specific decisions[5].

In spite of plenty of normative and descriptive researchers of decision making, a serious research gap is there in terms of the decision, aider's interest. Those research gaps are of three types: Specialty research, practice-driven research, and aid development [2]. The awareness of the behavioral aspect of decision making has grown yet; behavioral issues have not received a great deal of attention by decision analysis researchers in recent years [2].

B. Business Intelligence and Business Analytics:

Though multiplicity of definitions of Business intelligence [2] are available, typically Business intelligence and analytics are seen as a set of methods, technologies, and associated tools to improve business decision-making. Further, the term "Business Analytics" is used in replacement of the word "Business Intelligence". Analytics is not a new idea; it paves ways to find far beyond reference far back as the 1940s. It commands more attention in the late 1960s when the decision support system has aided by computers [3]. At that time, data storage was small and structured, and the majority of analytical activities has done through descriptive analytics [4]. Descriptive analytics [Business Intelligence (BI)] is the entry-level in analytics taxonomy. These systematic activities mainly deal to create reports on summarizing business activities to report past/ present status[5]. Data science was under discussion by academics in 2001 during the time of the Analytics 2.0 era began. In the early 2000s, both Big Data and advanced analytics (both predictive and prescriptive) started to emerge in the commercial world [6], and the movement from traditional Business Intelligence to real-time or right-time decision support data represented a real paradigm shift[7].

Though Big Data is an emerging phenomenon, in recent years, its validity in different industries and countries has made it a pertinent research area for academic and management studies [2]. A significant innovation in analytical techniques for Big Data has not taken place. Still, one anticipates the emergence of such novel analytics shortly. In the case of, real-time analytics will likely become a fertile field of research due to the growth of location-aware social media and mobile apps[6]. Even though there is enormous importance are there for Big Data, it is used limitedly for decision-making.

The idea of the term "real-time" differs from person to person, "right time" is the most practical term to describe the timely delivery of information to decision makers[3]. The moment when decision makers carried out decision making has termed as "real-time." The research gap is existing if real-time BI\&AA has any impact on cognitive constraints within decision-makers and human information processing capabilities[3].

\section{Selective Perception}

The thing which is even more important than the real-time analysis, our actions in response to analysis results that are performed in real-time to change parameters of business processes instantaneously[3]. There is a long time spent on event occurrence and decision maker's action; the lesser impact will be there in further decision[4].

Dearborn and Simon, in their early works, mention that managers process provide specific ideas perceiving those aspects of the situation that specifically parallel to the acts and goals of their department [5]. 
J.P.Walsh, after several decades, extended both Dearborn and Simon's study, on the concept of whether the functional experience has incorporated in the manager's belief structures, which in turn may affect managerial information processing. To some extent, their research results in little evidence of parochial information processing [6]. From the view of Schoemaker and Russo, numerous managerial decisions are yet resistant to technological and conceptual advances[7]. There are multiple information and technical solutions in large companies; from the view of Gigerenzer, in $50 \%$ of cases, managers have their business decision on their courage. Still, the lack of courage and trust keeps executives away from following it. Statistics portray that less knowledgeable people, though they lack in their financial savings, might make quick and accurate business decisions than intelligent computing systems or industry experts who have plenty of information available. Schoemaker and Tetlock wrote that several organization gives several restriction and taboos that give limit for the acts of managers in their thoughts, words, or actions. Some managers show their willingness to dramatic scenarios and land their organization in a situation where plans had not have made for what was, in fact, a predictable scenario.

D. Theoretical Framework

Business decisions have taken on two aspects; one side based on the managers requires data and information in their decision-making process, and on the other hand, it's based on gut feeling ignoring available information. Though fast technological progress in information gathering and display, the manager's decision has based on their gut feeling. In their view, information has considered as a system of belief, yet past research papers lack focus on real-time information delivery. It's still an open question that, whether the managers would stick in their decision even if the computer provides warnings and suggestions about the outcomes of the conclusion of changes in real-time. To overcome this literary gap, inductive research with the exploratory approach has performed. The most prominent question of this research is to find out how business decision-makers respond to real-time BI\&AA warnings.

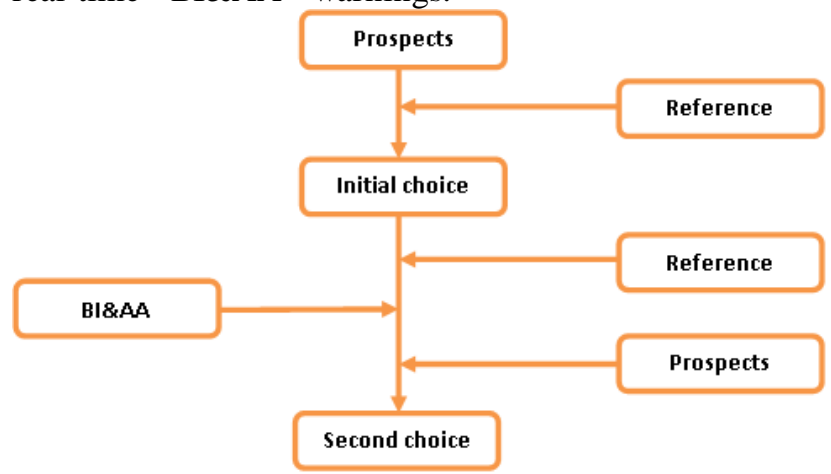

Figure 1. Theoretical framework
Figure 1 exhibits the theoretical framework of this research that results from the study of the literature review. This research will dwell deep if real-time BI\&AA warning may impact and even end in the change of decision linked to both negative and positive prospects. Literature implies risk aversion in options between positive and risk-seeking negative possibilities. It further paves ways to the formulation of the following hypotheses:

H1: Real-time BI\&AA warnings have a low impact on the change in the decision if the predicted loss for choice is smaller but specific.

H2: Real-time BI\&AA warnings have a high impact on the change in the decision if predicted loss choice is more extensive but merely probable.

H3: Real-time BI\&AA warnings will have a high impact on the change of decision if the foreseen gain for choice is minor but conformed.

H4: Real-time BI\&AA warnings have a low impact on the change of decision if the predicted gain for choice is more significant but merely probable.

\section{METHOD}

With the help of an online experiment, the authors of this research will explore if the information provided at the time of decision making made influences or changes the decision maker's mind and leads to different decision outcomes. The first experiment is kept to testify the prospect theory having reference points different than zero. Then the next test is to explore if BI\&AA warnings have an impact on the second choice.

In the first experiment, participants are asked to deal with eight of twelve marginal problem scenarios. Every individual is asked to their alternative choices of gains and losses in four scenes. According to Tversky- Kahneman probability - weighting function, the mathematical expectancy of prospects and certainty equivalent will be calculated.

While in the second experiment, participants are asked to read over the marginal problem under discussion and then asked to discuss the problem they read. Further to their decision, participants are provided with BI\&AA warnings about the estimated result of their decision and an opportunity to make a change.

MBA students with an experience of working are considered as an apt choice for this research. In order to overcome, student-manager surrogacy issue, senior managers have conducted experiments and are considered and used as a control group. Gender, Age, GPA, and education level are considered as control variables measured directly together 
with the industry where participants work in.

The highly important threat which affects the validity of experimental social science research findings is social desirability bias. Indirect questions or the use of proxy subjects is one of the techniques that reduce the desirable social bias. In order to control the validity of research, data will be analyzed, and proxy subject scenarios will be used for randomly selected participants.

\section{CONCLUSION}

In organizational decision-making processes, it is quite easy and possible to integrate predictive real-time BI\&AA warnings. It's still an open question, that how decision-makers will response to such notices and whether it will make an impact on their decision.

Research, which is all concerning BI\&AA on cognitive constrains, is missing. Here the research which is under discussion is contributing much to fill the gap. This research will contribute to both descriptive and prescriptive decision theory and will add to the existing literature in the field of BA and selective perception. At the time, warnings about decision consequences have provided besides findings from online experiments that will provide insights into the decision maker's behavior. The question, how to better design the BI\&AA system to support decision-makers will solved with the data supplied by detected tendencies with hints.

\section{ACKNOWLEDGEMENT}

The research paper is funded by RUSA (Rashtriya Uchchatar Shiksha Abhiyan) Phase 2.0 Scheme by Ministry of Human Resource Development (MHRD), India.

\section{REFERENCES}

1. Gartner, Inc. (2017, February 17). Gartner Says Worldwide Business Intelligence and Analytics Market to Reach $\$ 18.3$ Billion in 2017.Retrieved from https://www.gartner.com/newsroom/id/3612617

2. Gartner, Inc. (2017). Mastering the New Business Executive Job of the CIO. Insights From the 2018 CIO Agenda Report. Retrieved from https://www.gartner.com/imagesrv/ciotrends/pdf/cio_agenda_2018.pdf

3. Kielstra, P. (2007). In search of clarity Unravelling the complexities of executive decision-making. The Economist Intelligence Unit http://www.businessobjects.com/jump/emea/economist/report/ EIU_In_search_of_clarity_8_August_2007.pdf

4. Paradigm4. (2014, July 1). Leaving Data on the Table: New Survey Shows Variety, Not Volume, is the Bigger Challenge of Analyzing Big Data. Retrieved from http://www.prnewswire.com/newsreleases/leaving-data-on-the-table-new -survey-shows-variety-notvolume-is-the-bigger-challenge-of-analyzing-b ig-data-265365761.html

5. Gartner, Inc. (2015, September 15). Gartner Says Business Intelligence and Analytics Leaders Must Focus on Mindsets and Culture to Kick Start Advanced Analytics. Retrieved from http://www.gartner.com /newsroom /id/ 3130017

6. Forrester Research, Inc. (2014, October). Boost The Value Of Your Enterprise BI With Advanced Search. Retrieved from http://go.thoughtspot.com/forrester-white-paper-0315.html

7. Oracle. (2012, July 10). Big Data, Bigger Opportunities: Plans and Preparedness for the Data Deluge. Retrieved from http://www.oracle.com/us/industries/utilities/big-data-biggeropportunitie s-study-1881351.pdf 